\title{
Androgen receptor gene mutations in 258 Han Chinese patients with polycystic ovary syndrome
}

\author{
LIFENG TIAN $^{1-3}$, YANG ZOU $^{3,4}$, JUN TAN $^{2,3}$, YAOQING WANG $^{1}$, JIA CHEN $^{1}$, LEIZHEN XIA $^{2}$, \\ LIXIAN XU ${ }^{3}$, GE CHEN ${ }^{3,4}$, QIONGFANG WU ${ }^{2,3}$ and OUPING HUANG ${ }^{1,3,5}$ \\ ${ }^{1}$ Department of Gynecology and Obstetrics, Jiangxi Medical College, Graduate School of Nanchang University, \\ Nanchang, Jiangxi 330031; ${ }^{2}$ Reproductive Medicine Center, ${ }^{3}$ Key Laboratory of Women's Reproductive \\ Health of Jiangxi Province, ${ }^{4}$ Central Laboratory and the ${ }^{5}$ Department of Gynecology, Jiangxi \\ Provincial Maternal and Child Health Hospital, Nanchang, Jiangxi 330006, P.R. China
}

Received December 27, 2019; Accepted May 15, 2020

DOI: $10.3892 /$ etm.2020.9463

\begin{abstract}
Polycystic ovary syndrome (PCOS) affects 8-13\% of reproductive-age females worldwide and mutations or aberrant expression of androgen receptor (AR) may cause the onset of this disease. In the present study, 258 samples from Han Chinese patients with PCOS were analyzed for the presence of AR mutations via sequencing of all coding exons of the AR gene. A total of five heterozygous missense mutations, namely p.V3M, p.Q72R, p.S158L, p.S176R and p.G396R, were identified in five of the patients. Among these, p.S158L was a novel mutation that, to the best of our knowledge, has not been reported previously. Although the remaining four mutations have been reported previously, they existed at low frequencies or were absent in the control subjects and in the Exome Aggregation Consortium database. The results of evolutionary conservation and in silico analysis revealed that the p.V3M, p.S158L and p.S176R mutations were pathogenic, whereas the p.Q72R and p.G396R mutations were benign. Compared with the patients with PCOS without AR mutations or with benign AR mutations, markedly lower estrogen levels on the day of human chorionic gonadotropin injection were observed in the three patients with PCOS with potentially pathogenic mutations. In addition, patients with PCOS with pathogenic mutations had lower numbers of oocytes; however, the difference was not statistically significant. Of note, these observations should be interpreted with caution due to the relatively small sample size in the present study. Therefore, a larger number of samples should be collected to validate the results of the present study in future studies. In summary, the
\end{abstract}

Correspondence to: Professor Ouping Huang, Department of Gynecology and Obstetrics, Jiangxi Medical College, Graduate School of Nanchang University, 999 Xuefu Avenue, Honggutan New District, Nanchang, Jiangxi 330031, P.R. China

E-mail: happytlf@aliyun.com

Key words: polycystic ovary syndrome, androgen receptor, rare variant, Han Chinese present study identified three potential pathogenic mutations in 258 Han Chinese patients with PCOS and these mutations may have an implication in the pathogenesis of PCOS.

\section{Introduction}

Polycystic ovary syndrome (PCOS) is one of the most common endocrine disorders in females, affecting $8-13 \%$ of reproductive-age women $(1,2)$. It is a multifactorial disorder with a broad spectrum of clinical manifestations, characterized by elevated levels of luteinizing hormone ( $\mathrm{LH})$ and androgen, ovulatory dysfunction and irregular menstrual cycles, as well as the appearance of a polycystic ovarian morphology on ultrasound imaging.

Among patients with PCOS, 60-80\% suffer from hyperandrogenemia and most of them have slightly elevated levels of circulating androgens (3-5). The effects of androgen are mainly mediated via the androgen receptor (AR), a ligand-dependent nuclear transcription factor belonging to the steroid hormone nuclear receptor family. Increasing evidence has suggested that AR may serve roles in the development of PCOS (6-10). Previous studies have demonstrated that AR (CAG)n repeats (5) and rs6152A (6) gene polymorphisms are associated with the pathogenesis of PCOS (11-15). Xia et al (16) performed a case-control study involving 261 patients with PCOS and 278 healthy controls, revealing that shorter alleles of (CAG)n in exon 1 of the AR gene enhance the susceptibility to PCOS, either by upregulating AR activity or by causing hyperandrogenism. Mohlig et al (17) demonstrated that the AR CAG repeat polymorphism may result in metabolic disorders by modifying the impact of testosterone (T) on insulin resistance in PCOS, which is consistent with previous studies $(12,14)$. Splice variants of AR have been reported to occur in various androgen-sensitive types of cancer, including prostate cancer, breast cancer and liver cancer cell lines (18). Wang et al (19) proposed that somatic mutations in AR have an etiological role in the pathogenesis of PCOS. The study revealed that in the majority of PCOS samples, ovarian granulosa cells possess somatic insertions or deletions in the AR gene. These samples have a higher total serial T, serial dehydroepiandrosterone and follicular fluid free androgen 
index and only the insertion allele is associated with higher follicular fluid levels of anti-Müllerian hormone (AMH), a growth factor produced solely by small follicles (19-22). Furthermore, Nam et al (23) observed that a patient with AR-mutated PCOS gave birth to a baby girl with androgen insensitivity syndrome. Therefore, it was hypothesized that abnormally expressed and/or dysfunctional AR may serve certain roles in the pathogenesis of PCOS.

In the present study, a total of 258 Han Chinese patients with PCOS were recruited and analyzed for the presence of AR mutations with the aim of exploring the potential involvement of AR mutations in the pathogenesis of PCOS.

\section{Materials and methods}

Patients and blood samples. A total of 258 infertile females with PCOS (average age, 27.85 \pm 3.46 years; age range, 21-41 years) who underwent in vitro fertilization/intracytoplasmic sperm injection-embryo transfer (IVF/ICSI-ET) cycles were recruited at Jiangxi Provincial Maternal and Child Health Hospital (Nanchang, China) between October 2016 and September 2018. PCOS was diagnosed according to the Rotterdam criteria (24), requiring the presence of two of the following features: i) Oligo/anovulation; ii) hyperandrogenism; and iii) polycystic ovaries detected by ultrasound imaging. Hyperandrogenism was diagnosed on the basis of either hirsutism or hyperandrogenemia. Hirsutism was determined by means of a modified Ferriman-Gallwey score $>6$ (25). Hyperandrogenemia was defined as an elevated total $\mathrm{T}$ level according to laboratory criteria (normal level, 10.83-56.94 ng/ dl). Polycystic ovaries on ultrasound imaging were defined as the presence of $\geq 12$ antral follicles measuring $2-9 \mathrm{~mm}$ in diameter and/or an increased ovarian volume $\left(>10 \mathrm{~cm}^{3}\right)$ (26). Other causes of hyperandrogenism and ovulation dysfunction, including ovarian interstitial tumor or adrenal tumor, congenital adrenal hyperplasia, hyperprolactinemia and thyroid dysfunction, were ruled out.

Patients were excluded from the present study if they had congenital or acquired uterine malformations, including septate uterus, duplex uterus, adenomyosis, submucous myoma or intrauterine adhesion, abnormal results of chromosome karyotyping or medical conditions that contraindicated assisted reproductive technology or pregnancy. Patients with controlled diabetes and hypertension were not excluded. There were no male-factor exclusions and the use of donor semen was not allowed. In addition, a total of 520 female Han Chinese control (average age, 31.48 \pm 5.59 years; age range, 20-42 years) subjects without PCOS were recruited at Jiangxi Provincial Maternal and Child Health Hospital (Nanchang, China) between October 2016 and September 2018. Details of the cases and controls are provided in Table I.

Measurement of hormones and biochemical parameters. All hormones and biochemical indicators were assessed at the Clinical Laboratory of Jiangxi Provincial Maternal and Child Health Hospital (Nanchang, China). The basal levels of follicle-stimulating hormone (FSH), LH, estrogen (E2), $\mathrm{T}$, prolactin (PRL), AMH, free triiodothyronine (FT3), free thyroxine (FT4), thyroid-stimulating hormone (TSH) and cancer antigen 125 (CA125), and the levels of LH, progesterone and E2 on the day of human chorionic gonadotropin (hCG) injection were measured by radioimmunoassay methods as described previously (27). Fasting blood glucose (FBG), triglyceride, total cholesterol (TC), high-density lipoprotein cholesterol (HDL) and low-density lipoprotein cholesterol (LDL) levels were examined using a Beckman AU5800 fully automatic biochemical analyzer (Beckman Coulter, Inc.) and the gold-labeling method (28). Other clinical data, including age, duration of infertility, body mass index (BMI), antral follicle count (AFC), length of menstrual cycle, duration of ovarian stimulation, total dose of gonadotrophins and number of oocytes retrieved, were collected from the clinical records of the patients (Table I).

Mutational analysis of the AR gene. Genomic DNA was isolated from the peripheral blood samples of patients with PCOS using the DNeasy Blood kit (cat. no. 69504; Qiagen, Inc.) according to the manufacturer's protocol. The entire coding regions and the adjacent exon/intron boundaries of the AR gene were amplified by PCR with 10 sets of primer pairs (Table II). In brief, for each PCR amplification reaction, $\sim 50 \mathrm{ng}$ total DNA was used in a final volume of $30 \mu \mathrm{l}$, with the following amplification protocol: Initial pre-denaturation step at $94^{\circ} \mathrm{C}$ for $3 \mathrm{~min}$, followed by 35 cycles of denaturation at $94^{\circ} \mathrm{C}$ for $30 \mathrm{sec}$, annealing at different temperatures $\left(52-60^{\circ} \mathrm{C}\right.$; Table II) for $30 \mathrm{sec}$ and extension at $72^{\circ} \mathrm{C}$ for $30 \mathrm{sec}$; final extension at $72^{\circ} \mathrm{C}$ for $7 \mathrm{~min}$. PCR was performed using a Thermal Cycler 2720 (Applied Biosystems; Thermo Fisher Scientific, Inc.). The PCR amplification products were then purified and sequenced on an ABI Prism 3730 DNA sequencer (Applied Biosystems; Thermo Fisher Scientific, Inc.). An additional independent PCR amplification and DNA sequencing experiment was performed with samples of patients with PCOS harboring potential AR mutations. PCR amplification and DNA sequencing were performed as described above. The identified mutations were confirmed by bidirectional sequencing on ABI 3730 Prism DNA sequencer (Applied Biosystems; Thermo Fisher Scientific, Inc.).

Bioinformatics prediction of the pathogenicity of AR mutations. Two online bioinformatic programs, PolyPhen-2 (http:// genetics.bwh.harvard.edu/pph2/) (29) and MutationTaster (http://mutationtaster.org/) (30) were used to analyze the disease-causing potential of the identified missense mutations. Bioinformatics analysis was performed in July 2019. PolyPhen-2 and MutationTaster automatically assessed whether each mutation was either pathogenic or benign, respectively.

Evolutionary conservation analysis of AR mutations. The protein sequences from 14 vertebrate species in the GenBank database (https://www.ncbi.nlm.nih.gov/genbank/) were used to analyze the evolutionary conservation status of the AR mutations. The species included Homo sapiens (NP_000035), Pan troglodytes (XP_024208738), Rattus norvegicus (NP_036634), Sus scrofa (NP_999479), Bos taurus (NP_001231056), Canis lupus familiaris (NP_001003053), Equus caballus (NP_001157363), Felis catus (XP_023105265), Loxodonta africana (XP_003412790), Myotis brandtii (XP_003412790), Octodon degus (XP_004644568), Orycteropus afer 
Table I. Potential association analysis of clinical data and potential pathogenic mutations in the androgen receptor gene.

\begin{tabular}{|c|c|c|c|}
\hline \multirow[b]{2}{*}{ Parameter } & \multicolumn{2}{|r|}{ PCOS cases $(n=258)$} & \multirow[b]{2}{*}{ P-value ${ }^{a}$} \\
\hline & Mutation $(n=3)$ & Without or with benign mutations $(n=255)$ & \\
\hline Age (years) & $27.33 \pm 4.51$ & $27.86 \pm 3.46$ & 0.795 \\
\hline Duration of infertility (years) & $3.67 \pm 1.53$ & $4.12 \pm 2.48$ & 0.753 \\
\hline BMI $\left(\mathrm{kg} / \mathrm{m}^{2}\right)$ & $20.94 \pm 0.65$ & $23.33 \pm 3.4$ & 0.225 \\
\hline Basal FSH (IU/l) & $6.94 \pm 1.66$ & $5.82 \pm 1.39$ & 0.169 \\
\hline Basal LH (IU/l) & $9.92 \pm 0.81$ & $9.76 \pm 5.19$ & 0.803 \\
\hline LH/FSH & $1.48 \pm 0.36$ & $1.73 \pm 1.08$ & 0.690 \\
\hline Basal E2 (pg/ml) & $41.45 \pm 14.4$ & $55.03 \pm 99.94$ & 0.252 \\
\hline Basal T (ng/dl) & $44.12 \pm 13.87$ & $60.29 \pm 210.68$ & 0.317 \\
\hline Basal PRL (ng/ml) & $17.71 \pm 6.08$ & $16.33 \pm 14.62$ & 0.870 \\
\hline AMH (ng/ml) & $6.52 \pm 1.71$ & $9.28 \pm 4.95$ & 0.337 \\
\hline FT3 (pg/ml) & $3.26 \pm 0.44$ & $3.36 \pm 0.41$ & 0.677 \\
\hline FT4 (ng/dl) & $1.44 \pm 0.05$ & $1.43 \pm 1.03$ & 0.813 \\
\hline TSH (mIU/l) & $1.95 \pm 0.31$ & $2.4 \pm 1.79$ & 0.665 \\
\hline CA125 (U/ml) & $22.79 \pm 26.25$ & $17.67 \pm 25.23$ & 0.727 \\
\hline $\mathrm{FBG}(\mathrm{mM})$ & $4.9 \pm 0.17$ & $4.84 \pm 0.5$ & 0.828 \\
\hline Triglyceride (mM) & $0.72 \pm 0.23$ & $1.39 \pm 0.95$ & 0.226 \\
\hline $\mathrm{TC}(\mathrm{mM})$ & $4.02 \pm 0.46$ & $4.46 \pm 0.81$ & 0.349 \\
\hline $\operatorname{HDL}(\mathrm{mM})$ & $1.26 \pm 0.24$ & $1.25 \pm 0.27$ & 0.926 \\
\hline LDL (mM) & $2.43 \pm 0.34$ & $2.58 \pm 0.74$ & 0.730 \\
\hline $\mathrm{AFC}(\mathrm{n})$ & $19.00 \pm 3.61$ & $23.27 \pm 5.28$ & 0.164 \\
\hline Length of menstrual cycle (days) & $45.83 \pm 13.77$ & $63.81 \pm 42.25$ & 0.463 \\
\hline Duration of ovarian stimulation (days) & $12.00 \pm 1.73$ & $12.99 \pm 2.93$ & 0.559 \\
\hline Total dose of gonadotrophins (IU) & $1404.17 \pm 199.35$ & $1989.85 \pm 954.69$ & 0.290 \\
\hline Oocytes retrieved (n) & $13.33 \pm 2.52$ & $17.08 \pm 7.94$ & 0.416 \\
\hline LH level on hCG injection day (IU/l) & $1.40 \pm 0.58$ & $0.94 \pm 0.77$ & 0.304 \\
\hline Progesterone level on hCG injection day $(\mathrm{ng} / \mathrm{ml})$ & $0.78 \pm 0.22$ & $0.62 \pm 0.33$ & 0.426 \\
\hline E2 level on hCG injection day (pg/ml) & $2227.00 \pm 184.82$ & $3180.24 \pm 1710.25$ & $<0.001$ \\
\hline 2PN fertilized oocytes (n) & $10.00 \pm 2.00$ & $11.01 \pm 6.04$ & 0.772 \\
\hline Available embryos (n) & $6.33 \pm 1.53$ & $4.67 \pm 2.89$ & 0.322 \\
\hline High-quality embryos (n) & $3.67 \pm 2.52$ & $2.69 \pm 2.50$ & 0.500 \\
\hline Embryo transfer rate & $1 / 3(33.33)$ & $146 / 255(57.25)$ & 0.579 \\
\hline Clinical pregnancy rate & $1 / 1(100)$ & $98 / 142(69.01)$ & 1.000 \\
\hline
\end{tabular}

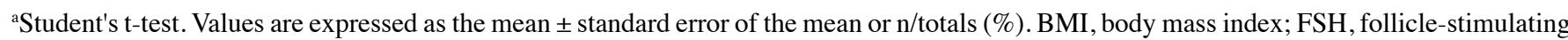
hormone; LH, luteinizing hormone; E2, estrogen; T, testosterone; PRL, prolactin; AMH, anti-Müllerian hormone; FT3, free triiodothyronine; FT4, free thyroxine; TSH, thyroid-stimulating hormone; CA125, cancer antigen 125; FBG, fasting blood glucose; TG, triglyceride; TC, total cholesterol; HDL, high-density lipoprotein cholesterol; LDL, low-density lipoprotein cholesterol; AFC, antral follicle count; hCG, human chorionic gonadotropin; PN, pronucleus; PCOS, polycystic ovary syndrome.

(XP_007954477), Ovis aries (NP_001295513) and Acinonyx jubatus (XP_026909508). Multiple sequence alignment was performed using the 'ClustalW' tool of the alignment function in the Molecular Evolutionary Genetics Analysis software (version 4.0) which was created and developed by Kumar et al (31).

Statistical analysis. Clinical data and the frequency differences of AR mutations were analyzed by two-tailed Fisher's exact tests using SPSS software (version 18.0; SPSS, Inc.). Continuous quantitative data are expressed as the mean \pm standard deviation. Differences among groups were compared using Student's t-test. $\mathrm{P}<0.05$ was considered to indicate a statistically significant difference.

\section{Results}

AR mutations. In the present study, all eight coding exons of the AR gene were sequenced for the presence of AR mutations in 258 samples from patients with PCOS. A total of five heterozygous missense mutations, p.V3M (c.7G>A), p.Q72R (c.215A > G), p.S158L (c.473C >T), p.S176R (c.528C >A) and p.G396R (c.1186G $>$ C), were identified in 5/258 PCOS samples (Fig. 1; Table III). Among these mutations, p.S158L was 
Table II. Primers for PCR mutational analyses of the androgen receptor gene.

\begin{tabular}{lcllc}
\hline $\begin{array}{l}\text { Target } \\
\text { region }\end{array}$ & $\begin{array}{c}\text { Annealing } \\
\text { temperature }\left({ }^{\circ} \mathrm{C}\right)\end{array}$ & \multicolumn{1}{c}{$\begin{array}{c}\text { Forward primer } \\
\left(5^{\prime}-3^{\prime}\right)\end{array}$} & \multicolumn{1}{c}{$\begin{array}{c}\text { Reverse primer } \\
\left(5^{\prime}-3^{\prime}\right)\end{array}$} & $\begin{array}{c}\text { PCR amplicon } \\
\text { length }(\mathrm{bp})\end{array}$ \\
\hline Exon 1-1 & 52 & GTGGGCAGCTAGCTGCAGC & GTAATTGTCCTTGGAGGA & 789 \\
Exon 1-2 & 56 & ACAGCAGCAGGAAGCAGT & AGGTCCCCATAGCGGCACT & 645 \\
Exon 1-3 & 54 & CCACGCTCGCATCAAGCTG & ACGGGAGAGCTCTAGGTT & 611 \\
Exon 2 & 55 & GCAGGTTAATGCTGAAGAC & CTCCTAAGTTATTTGATAG & 377 \\
Exon 3 & 58 & TCATGTGGTAGGATATAAT & TGGCTGATGGCCACGTTGC & 388 \\
Exon 4 & 58 & AAGGAGTTTAGAGTCTGTG & ATTGAGACTTGTAACAAT & 571 \\
Exon 5 & 52 & TAGGGGATGCCCGAATACC & GCCAGTTGGCTGAAAGCC & 430 \\
Exon 6 & 50 & TCCCTGGAGCACCAGCAGG & TTGTTTCTTGTTAGGAA & 442 \\
Exon 7 & 60 & AGCACACAGACTTCAACTA & TTCACAATATCCAGCTGG & 497 \\
Exon 8 & 55 & TCGCTGTCTCTCTCTAACA & TGTGGCTGGCACAGAGTA & 693 \\
\hline
\end{tabular}

Table III. Androgen receptor mutations identified in the present study.

\begin{tabular}{|c|c|c|c|c|c|c|c|c|c|}
\hline Mutation & $\begin{array}{l}\text { Polyphen-2 } \\
\text { prediction }\end{array}$ & $\begin{array}{l}\text { MutationTaster } \\
\text { prediction }\end{array}$ & $\begin{array}{l}\text { ID in } \\
\text { dbSNP }\end{array}$ & $\begin{array}{c}\text { Novel } \\
\text { mutation }\end{array}$ & $\begin{array}{c}\text { PCOS } \\
\text { cases } \\
(\mathrm{n}=258)\end{array}$ & $\begin{array}{l}\text { Control } \\
\text { subjects } \\
(\mathrm{n}=520)\end{array}$ & P-value & EXAC & P-value \\
\hline p.V3M & $\begin{array}{l}\text { Probably } \\
\text { damaging }\end{array}$ & Disease-causing & rs778912582 & No & $1 / 516$ & $0 / 1040$ & 0.332 & $5 / 73236$ & 0.041 \\
\hline p.Q72R & Benign & Polymorphism & rs767121593 & No & $1 / 516$ & $0 / 1040$ & 0.332 & $0 / 48582$ & 0.011 \\
\hline p.S158L & $\begin{array}{l}\text { Probably } \\
\text { damaging }\end{array}$ & Disease-causing & - & Yes & $1 / 516$ & $0 / 1040$ & 0.332 & $0 / 43682$ & 0.012 \\
\hline p.S176R & $\begin{array}{l}\text { Probably } \\
\text { damaging }\end{array}$ & Disease-causing & rs777131133 & No & $1 / 516$ & 0/1040 & 0.332 & $45 / 39906$ & 0.446 \\
\hline p.G396R & Benign & Polymorphism & rs202150225 & No & $1 / 516$ & $1 / 1040$ & 0.553 & $4 / 28463$ & 0.086 \\
\hline
\end{tabular}

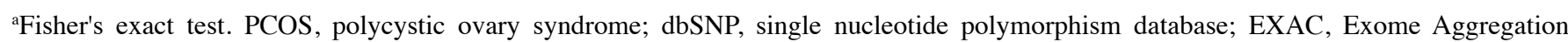
Consortium database.

a novel mutation and, to the best of our knowledge, has not been reported previously. In addition, it was not detected in either the 520 Han Chinese control subjects or in the Exome Aggregation Consortium (EXAC) database. The remaining four mutations were previously reported in public databases; however, they were absent or only detected in the 520 Han Chinese control subjects and the EXAC database at low frequencies (Table III). Compared with the 520 Chinese patients without PCOS, the mutation frequency of each of the five AR mutations exhibited no statistically significant difference; however, three of these mutations, p.V3M, p.Q72R and p.S158L, exhibited significant differences in mutation frequency when compared with those in the EXAC database $(\mathrm{P}<0.05)$.

Evolutionary conservation and in silico analysis of AR mutations. Evolutionary conservation analysis revealed that three AR mutations, p.V3M, p.S158L and p.S176R, were highly conserved among the 14 vertebrate species ranging from Homo sapiens to Acinonyx jubatus, while the p.Q72R and p.G396R mutations were not generally conserved among these vertebrate species, except for Orycteropus afer and Octodon degus for p.Q72R and Octodon degus for p.G396R (Fig. 2).
Furthermore, in silico analysis of these mutations demonstrated that the p.V3M, p.S158L and p.S176R mutations were pathogenic, while the p.Q72R and p.G396R mutations were likely to be benign. These combined results implicated that p.V3M, p.S158L and p.S176R, but not the p.Q72R and p.G396R mutations, may be pathogenic.

Clinical characteristics of patients with PCOS. The general clinical features of the 258 patients with PCOS are summarized in Table I. The detailed clinical features of the 3 patients with PCOS with potential pathogenic AR mutations (p.V3M, p.S158L and p.S176R) are listed in Table IV. In brief, the average BMI was $20.94 \pm 0.65 \mathrm{~kg} / \mathrm{m}^{2}$ and the average basal levels of serum FSH, LH, E2 and T were 6.94 $\pm 1.66 \mathrm{IU} / 1$, $9.92 \pm 0.81 \mathrm{IU} / 1,41.45 \pm 14.4 \mathrm{pg} / \mathrm{ml}$ and $44.12 \pm 13.87 \mathrm{ng} / \mathrm{dl}$, respectively. The average serum AMH level was $6.52 \pm 1.71 \mathrm{ng} /$ $\mathrm{ml}$ and the average serum levels of FBG, triglyceride, TC, HDL and LDL were 4.9 $\pm 0.17,0.72 \pm 0.23,4.02 \pm 0.46,1.26 \pm 0.24$ and $2.43 \pm 0.34 \mathrm{mM}$, respectively. Of note, the patient with the p.S158L mutation was 27 years old and had slightly elevated serum levels of T $(57.51 \mathrm{ng} / \mathrm{dl})$ and FT3 $(3.75 \mathrm{pg} / \mathrm{ml})$, while the patient with the p.S176R mutation was 23 years old and had 

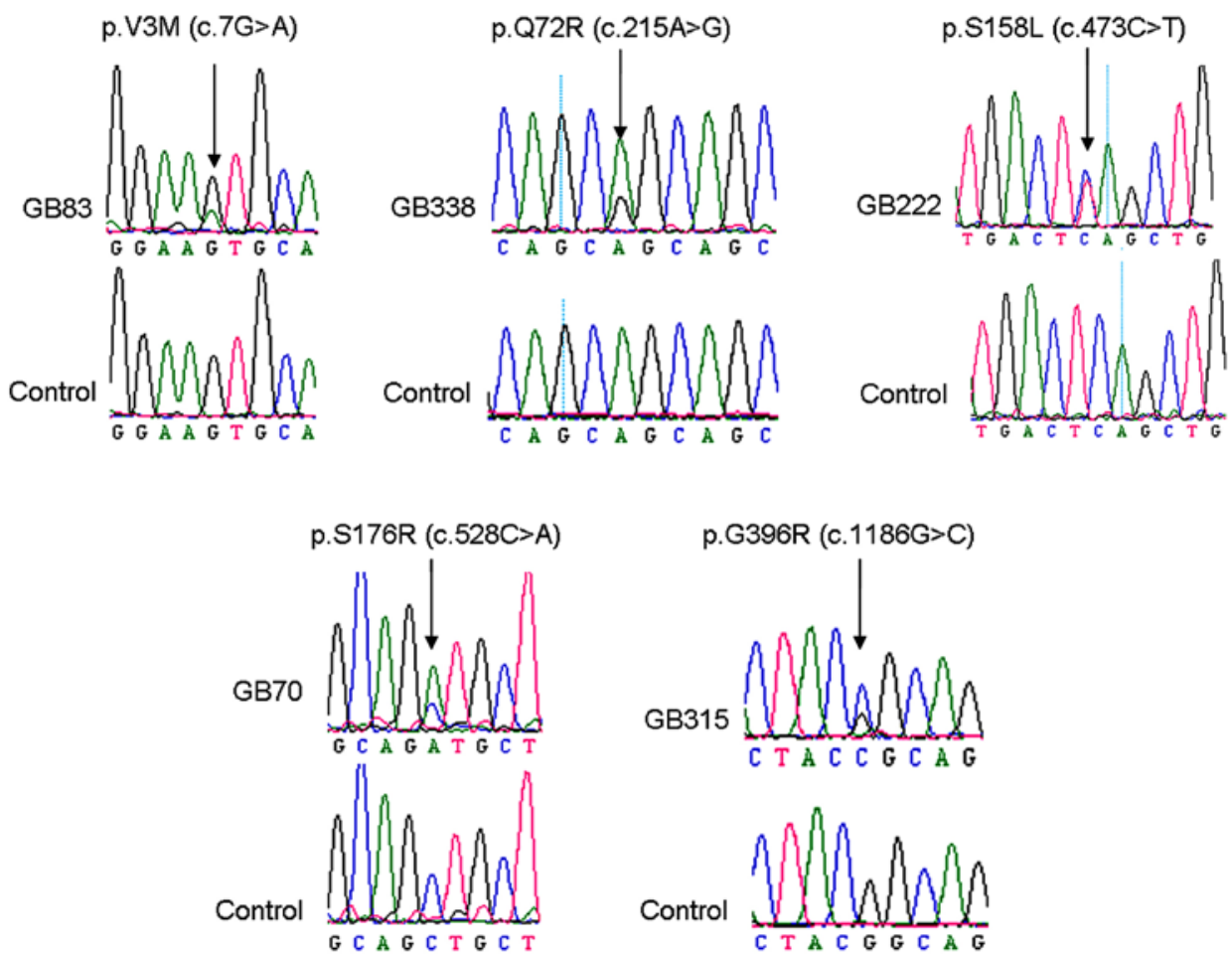

Figure 1. Sequencing electropherograms of androgen receptor mutations. The arrows indicate the locations of the mutations.

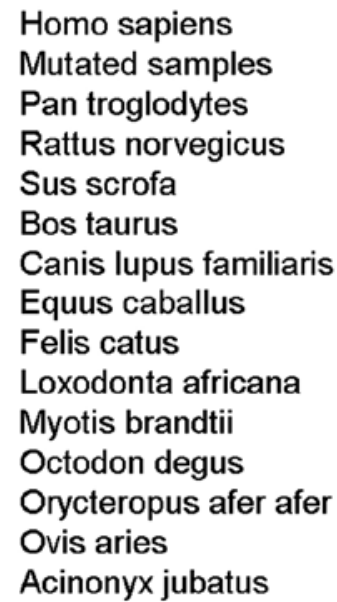

Homo sapiens

Mutated samples

Pan troglodytes

Rattus norvegicus

Equus caballus

Felis catus

Loxodonta africana

Myotis brandtii

Octodon degus

Ovis aries

Acinonyx jubatus
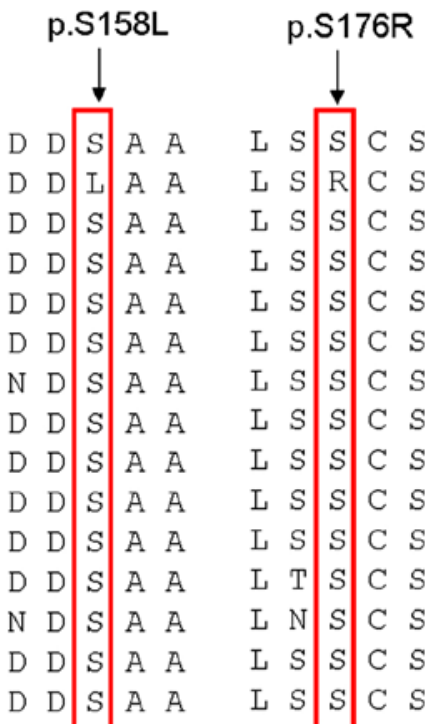

Figure 2. Evolutionary conservation analysis of androgen receptor mutations in 14 different vertebrate species from Homo sapiens to Acinonyx jubatus.

elevated serum levels of CA125 (52.96 U/ml). However, for the patient with the p.V3M mutation (age, 32 years), no distinctly aberrant clinical parameters were identified.

Associations between AR mutations and clinical features. In the present study, the differences in demographic and clinical characteristics between the three patients with PCOS with potential pathogenic AR mutations (p.V3M, p.S158L and p.S176R) were compared with those of the remaining 255 patients with PCOS without AR mutations or with likely benign AR mutations. The average serum E2 level on the day of hCG injection in the three patients with pathogenic AR mutations was $2,227.00 \pm 184.82 \mathrm{pg} / \mathrm{ml}$, which was significantly lower than that of the 255 patients with PCOS with benign AR mutations or without AR mutations $(3,180.24 \pm 1,710.25 \mathrm{pg} / \mathrm{ml}$; $\mathrm{P}<0.01$ (Table I).

\section{Discussion}

Previous studies have demonstrated that androgens serve crucial roles in the regulatory process of follicle development. They mediate their regulatory actions mainly via their specific AR receptors, affecting the transcription and translation of multiple female follicle development-associated downstream 
Table IV. Detailed clinical characteristics of the three patients with polycystic ovary syndrome with potential pathogenic androgen receptor mutations.

\begin{tabular}{|c|c|c|c|c|}
\hline Parameter & p.V3M & p.S158L & p.S176R & Reference range \\
\hline Age (years) & 32 & 27 & 23 & - \\
\hline Duration of infertility (years) & 4 & 2 & 5 & - \\
\hline BMI $\left(\mathrm{kg} / \mathrm{m}^{2}\right)$ & 20.83 & 20.36 & 21.64 & $18.50-25.00$ \\
\hline Basal FSH (IU/l) & 8.85 & 6.08 & 5.89 & $3.03-8.08$ \\
\hline Basal LH (IU/l) & 9.57 & 10.84 & 9.34 & $1.80-11.78$ \\
\hline Basal E2 (pg/ml) & 56.78 & 39.38 & 28.2 & $21.00-251.00$ \\
\hline Basal T (ng/dl) & 45.04 & 57.51 & 29.82 & $10.83-56.94$ \\
\hline Basal PRL (ng/ml) & 21.12 & 10.69 & 21.33 & $5.18-26.53$ \\
\hline $\mathrm{AMH}(\mathrm{ng} / \mathrm{ml})$ & 6.16 & 5.02 & 8.38 & $\begin{array}{l}20-29 \text { year-olds: } 1.18-9.49 \\
\text { 30-39 year-olds: } 0.67-5.24\end{array}$ \\
\hline FT3 (pg/ml) & 2.91 & 3.75 & 3.11 & $1.71-3.71$ \\
\hline FT4 (ng/dl) & 1.46 & 1.39 & 1.48 & $0.70-1.48$ \\
\hline TSH (mIU/l) & 2.13 & 2.13 & 1.59 & $0.35-4.95$ \\
\hline CA125 (U/ml) & 10.2 & 5.21 & 52.96 & $0.00-35.00$ \\
\hline FBG (mM) & 4.8 & 5.1 & 4.8 & $3.90-6.10$ \\
\hline TG (mM) & 0.69 & 0.97 & 0.51 & $0.34-1.69$ \\
\hline $\mathrm{TC}(\mathrm{mM})$ & 3.68 & 4.54 & 3.84 & $0.00-5.20$ \\
\hline HDL (mM) & 1.01 & 1.3 & 1.48 & $0.90-2.00$ \\
\hline $\mathrm{LDL}(\mathrm{mM})$ & 2.36 & 2.8 & 2.13 & $0.00-3.74$ \\
\hline $\mathrm{AFC}(\mathrm{n})$ & 15 & 22 & 20 & - \\
\hline Length of menstrual cycle (days) & 45 & 32.5 & 60 & - \\
\hline \multicolumn{5}{|l|}{ Duration of ovarian } \\
\hline stimulation (days) & 14 & 11 & 11 & - \\
\hline Total dose of gonadotrophins (IU) & 1625 & 1237.5 & 1350 & - \\
\hline Oocytes retrieved (n) & 11 & 13 & 16 & - \\
\hline \multicolumn{5}{|l|}{ LH level on } \\
\hline hCG injection day (IU/l) & 1.17 & 2.06 & 0.98 & - \\
\hline \multicolumn{5}{|l|}{ Progesterone level on hCG } \\
\hline injection day (ng/ml) & 0.86 & 0.53 & 0.94 & - \\
\hline \multicolumn{5}{|l|}{ E2 level on hCG } \\
\hline injection day (pg/ml) & 2109 & 2132 & 2440 & - \\
\hline 2PN fertilized oocytes (n) & 8 & 12 & 10 & \\
\hline Available embryos (n) & 5 & 8 & 6 & \\
\hline Fresh embryos transferred (n) & 0 & 0 & 2 & \\
\hline Clinical outcomes & $\begin{array}{l}\text { All embryos } \\
\text { frozen }\end{array}$ & $\begin{array}{l}\text { All embryos } \\
\text { frozen }\end{array}$ & $\begin{array}{l}\text { Delivery of } \\
2 \text { newborns }\end{array}$ & \\
\hline
\end{tabular}

BMI, body mass index; FSH, follicle-stimulating hormone; LH, luteinizing hormone; E2, estrogen; T, testosterone; PRL, prolactin; $\mathrm{AMH}$, anti-Müllerian hormone; FT3, free triiodothyronine; FT4, free thyroxine; TSH, thyroid-stimulating hormone; CA125, cancer antigen 125; FBG, fasting blood glucose; TG, triglyceride; TC, total cholesterol; HDL, high-density lipoprotein cholesterol; LDL, low-density lipoprotein cholesterol; AFC, antral follicle count; hCG, human chorionic gonadotropin; PN, pronucleus.

target genes $(32,33)$. Furthermore, previous studies have revealed that nucleotide change $(19,34)$ or aberrant expression $(32,35)$ of AR may promote the progression of PCOS.

In the present study, a total of five AR missense mutations were detected among 258 Han Chinese patients with PCOS. Among these, p.S158L was a novel mutation which, to the best of our knowledge, has not been reported previously. It was neither detected in the 520 Han Chinese control subjects nor in the EXAC database. Furthermore, the evolutionary conservation and in silico analysis results suggested that the p.S158L mutation may be harmful. Of note, the patient with the p.S158L mutation had slightly elevated serum levels of T and FT3. It was speculated that the increased level of T may be attributed to partial androgen insensitivity caused by the mutation. However, this hypothesis requires further validation by in vitro or in vivo studies.

Among the remaining four mutations, the p.V3M and p.S176R mutations have been reported in the EXAC database with low frequency, while they were not detected in the 520 Han 
Chinese control subjects. The evolutionary conservation and in silico analysis results revealed that these two mutations may be pathogenic. On the other hand, it was speculated that the p.Q72R and p.G396R mutations may be benign based on the evolutionary conservation and in silico analysis results.

In the present study, the potential association between the three pathogenic AR mutations and available clinical characteristics, including age, duration of infertility, BMI, basal levels of FSH, LH, E2, T and PRL, AMH, FT3, FT4, TSH, CA125, FBG, triglyceride, TC, HDL, LDL, AFC, length of menstrual cycle, duration of ovarian stimulation, total dose of gonadotrophins, number of oocytes retrieved, the levels of $\mathrm{LH}$, progesterone and E2 on the day of hCG injection, 2PN fertilized oocytes, number of available embryos, number of high-quality embryos, embryo transfer rate and clinical pregnancy rate, was analyzed. Compared with the 255 patients with PCOS with benign AR mutations or without AR mutations, significantly lower serum E2 levels on the day of hCG injection were observed in the three patients with PCOS with potentially pathogenic AR mutations $(\mathrm{P}<0.01)$. Furthermore, the patients with AR mutations had a lower number of oocytes retrieved; however, this difference was not statistically significant. In addition, no significant association was observed between AR mutations and any of the other clinical parameters.

It should be noted that the present study had certain limitations. First, the clinical observations should be treated with caution due to the relatively small sample size of patients with AR mutations $(n=3)$ in the present study. A larger number of samples should be collected to confirm these observations in a future study. Furthermore, the collection scope of samples was limited to IVF/ICSI-ET and there may be potential selection bias due to the setting of the present study (IVF clinic). Finally, for the AR mutations identified, only a bioinformatics analysis was performed and functional analysis in vitro is required in a future study to understand the role of the AR gene in the pathogenesis of PCOS.

In summary, the present study identified a total of three potential pathogenic mutations in 258 Han Chinese patients with PCOS and the current study hypothesizes that these mutations may serve a role in the pathogenesis of PCOS.

\section{Acknowledgements}

Not applicable.

\section{Funding}

The present study was supported by the GanPo Outstanding Talents 555 Project of Jiangxi Province, China, to $\mathrm{OH}$ and the Social Development Foundation of Jiangxi Province, China (grant no. 20151BBG70100 to LT).

\section{Availability of data and materials}

All data generated or analyzed during this study are included in this published article.

\section{Authors' contributions}

LT performed the experiments and prepared the manuscript. JT, YW, LXu and GC performed mutation screening.
YZ performed conservation and mutation analysis. LXi performed data analysis. YW and JC collected the samples and data analysis. $\mathrm{OH}$ and QW designed the study and revised the manuscript. All authors read and approved the final manuscript.

\section{Ethics approval and consent to participate}

The present study was approved by the Institutional Review Board of Jiangxi Provincial Maternal and Child Health Hospital (Nanchang, China) and written informed consent was obtained from all patients prior to the study. The present study was performed according to the Declaration of Helsinki and the ethical guidelines of Jiangxi Provincial Maternal and Child Health Hospital (Nanchang, China).

\section{Patient consent for publication}

Not applicable.

\section{Competing interests}

The authors declare that they have no competing interests.

\section{References}

1. Teede H, Deeks A and Moran L: Polycystic ovary syndrome: A complex condition with psychological, reproductive and metabolic manifestations that impacts on health across the lifespan. BMC Med 8: 41, 2010.

2. Azziz R, Carmina E, Chen Z, Dunaif A, Laven JS, Legro RS, Lizneva D, Natterson-Horowtiz B, Teede HJ and Yildiz BO: Polycystic ovary syndrome. Nat Rev Dis Primers 2: 16057, 2016.

3. Azziz R, Carmina E, Dewailly D, Diamanti-Kandarakis E, Escobar-Morreale HF, Futterweit W, Janssen OE, Legro RS, Norman RJ, Taylor AE, et al; Androgen Excess Society: Positions statement: Criteria for defining polycystic ovary syndrome as a predominantly hyperandrogenic syndrome: An Androgen Excess Society guideline. J Clin Endocrinol Metab 91: 4237-4245, 2006.

4. Chang WY, Knochenhauer ES, Bartolucci AA and Azziz R: Phenotypic spectrum of polycystic ovary syndrome: Clinical and biochemical characterization of the three major clinical subgroups. Fertil Steril 83: 1717-1723, 2005.

5. Livadas S, Pappas C, Karachalios A, Marinakis E, Tolia N, Drakou M, Kaldrymides P,Panidis D and Diamanti-Kandarakis E: Prevalence and impact of hyperandrogenemia in 1,218 women with polycystic ovary syndrome. Endocrine 47: 631-638, 2014.

6. Owens LA, Kristensen SG, Lerner A, Christopoulos G, Lavery S, Hanyaloglu AC, Hardy K, Yding Andersen C and Franks S: Gene expression in granulosa cells from small antral follicles from women with or without polycystic ovaries. J Clin Endocrinol Metab 104: 6182-6192, 2019.

7. Younas K, Quintela M, Thomas S, Garcia-Parra J, Blake L, Whiteland H, Bunkheila A, Francis LW, Margarit L, Gonzalez D, et al: Delayed endometrial decidualisation in polycystic ovary syndrome; the role of AR-MAGEA11. J Mol Med (Berl) 97: 1315-1327, 2019.

8. Xu G, Wang Q, Zhang AD, Liu JD, Feng JW and Chen YL: Effect of electroacupuncture at different acupoints on steroid hormones and ovarian androgen receptor expression in polycystic ovary syndrome rats. Zhen Ci Yan Jiu 43: 543-549, 2018.

9. Li X, Pishdari B, Cui P, Hu M, Yang HP, Guo YR, Jiang HY, Feng Y, Billig $\mathrm{H}$ and Shao R: Regulation of androgen receptor expression alters AMPK phosphorylation in the endometrium: In vivo and in vitro studies in women with polycystic ovary syndrome. Int J Biol Sci 11: 1376-1389, 2015.

10. Caldwell AS, Edwards MC, Desai R, Jimenez M, Gilchrist RB, Handelsman DJ and Walters KA: Neuroendocrine androgen action is a key extraovarian mediator in the development of polycystic ovary syndrome. Proc Natl Acad Sci USA 114: E3334-E3343, 2017. 
11. Rajender S, Carlus SJ, Bansal SK, Negi MP, Sadasivam N, Sadasivam MN and Thangaraj K: Androgen receptor CAG repeats length polymorphism and the risk of polycystic ovarian syndrome (PCOS). PLoS One 8: e75709, 2013.

12. Peng CY, Xie HJ, Guo ZF, Nie YL, Chen J, Zhou JM and Yin J: The association between androgen receptor gene CAG polymorphism and polycystic ovary syndrome: A case-control study and meta-analysis. J Assist Reprod Genet 31: 1211-1219, 2014.

13. Schüring AN, Welp A, Gromoll J, Zitzmann M, Sonntag B, Nieschlag E, Greb RR and Kiesel L: Role of the CAG repeat polymorphism of the androgen receptor gene in polycystic ovary syndrome (PCOS). Exp Clin Endocrinol Diabetes 120: 73-79, 2012.

14. Ibáñez L, Ong KK, Mongan N, Jääskeläinen J, Marcos MV, Hughes IA, De Zegher F and Dunger DB: Androgen receptor gene CAG repeat polymorphism in the development of ovarian hyperandrogenism. J Clin Endocrinol Metab 88: 3333-3338, 2003.

15. Kim JJ, Choung SH, Choi YM, Yoon SH, Kim SH and Moon SY: Androgen receptor gene CAG repeat polymorphism in women with polycystic ovary syndrome. Fertil Steril 90: 2318-2323, 2008.

16. Xia Y, Che Y, Zhang X, Zhang C, Cao Y, Wang W, Xu P, Wu X, Yi L, Gao Q, et al: Polymorphic CAG repeat in the androgen receptor gene in polycystic ovary syndrome patients. Mol Med Rep 5: 1330-1334, 2012.

17. Möhlig M, Jürgens A, Spranger J, Hoffmann K, Weickert MO, Schlösser HW, Schill T, Brabant G, Schüring A, Pfeiffer AF, et al: The androgen receptor CAG repeat modifies the impact of testosterone on insulin resistance in women with polycystic ovary syndrome. Eur J Endocrinol 155: 127-130, 2006.

18. Hu DG, Hickey TE, Irvine C, Wijayakumara DD, Lu L, Tilley WD, Selth LA and Mackenzie PI: Identification of androgen receptor splice variant transcripts in breast cancer cell lines and human tissues. Horm Cancer 5: 61-71, 2014.

19. Wang F, Pan J, Liu Y, Meng Q, Lv P, Qu F, Ding GL, Klausen C, Leung PC, Chan HC, et al: Alternative splicing of the androgen receptor in polycystic ovary syndrome. Proc Natl Acad Sci USA 112: 4743-4748, 2015.

20. Walters KA and Handelsman DJ: Androgen receptor splice variants and polycystic ovary syndrome: Cause or effect? Asian J Androl 18: 442-443, 2016.

21. Wadosky KM and Koochekpour S: Androgen receptor splice variants and prostate cancer: From bench to bedside. Oncotarget 8: 18550-18576, 2017.

22. Hickey TE, Irvine CM, Dvinge $H$, Tarulli GA, Hanson AR, Ryan NK, Pickering MA, Birrell SN, Hu DG, Mackenzie PI, et al: Expression of androgen receptor splice variants in clinical breast cancers. Oncotarget 6: 44728-44744, 2015.
23. Nam H, Kim CH, Cha MY, Kim JM, Kang BM and Yoo HW: Polycystic ovary syndrome woman with heterozygous androgen receptor gene mutation who gave birth to a child with androgen insensitivity syndrome. Obstet Gynecol Sci 58: 179-182, 2015.

24. Rotterdam ESHRE/ASRM-Sponsored PCOS Consensus Workshop Group: Revised 2003 consensus on diagnostic criteria and long-term health risks related to polycystic ovary syndrome. Fertil Steril 81: 19-25, 2004.

25. Hatch R, Rosenfield RL, Kim MH and Tredway D: Hirsutism: Implications, etiology, and management. Am J Obstet Gynecol 140: 815-830, 1981.

26. Balen AH, Laven JS, Tan SL and Dewailly D: Ultrasound assessment of the polycystic ovary: International consensus definitions. Hum Reprod Update 9: 505-514, 2003.

27. Wu J, Zou Y, Luo Y, Guo JB, Liu FY, Zhou JY, Zhang ZY, Wan L and Huang OP: Prevalence and clinical significance of mediator complex subunit 12 mutations in 362 Han Chinese samples with uterine leiomyoma. Oncol Lett 14: 47-54, 2017.

28. Li GX, Jiao XH and Cheng XB: Correlations between blood uric acid and the incidence and progression of type 2 diabetes nephropathy. Eur Rev Med Pharmacol Sci 22: 506-511, 2018.

29. Adzhubei IA, Schmidt S, Peshkin L, Ramensky VE, Gerasimova A, Bork P, Kondrashov AS and Sunyaev SR: A method and server for predicting damaging missense mutations. Nat Methods 7: 248-249, 2010.

30. Schwarz JM, Cooper DN, Schuelke M and Seelow D: MutationTaster2: Mutation prediction for the deep-sequencing age. Nat Methods 11: 361-362, 2014.

31. Kumar S, Stecher G and Tamura K: MEGA7: Molecular evolutionary genetics analysis version 7.0 for bigger datasets. Mol Biol Evol 33: 1870-1874, 2016.

32. Walters KA, Rodriguez Paris V, Aflatounian A and Handelsman DJ: Androgens and ovarian function: translation from basic discovery research to clinical impact. J Endocrinol 242: R23-R50, 2019

33. Walters KA and Handelsman DJ: Role of androgens in the ovary. Mol Cell Endocrinol 465: 36-47, 2018.

34. Baculescu N: The role of androgen receptor activity mediated by the CAG repeat polymorphism in the pathogenesis of PCOS. J Med Life 6: 18-25, 2013.

35. Lim JJ, Lima PDA, Salehi R, Lee DR and Tsang BK: Regulation of androgen receptor signaling by ubiquitination during folliculogenesis and its possible dysregulation in polycystic ovarian syndrome. Sci Rep 7: 10272, 2017.

This work is licensed under a Creative Commons Attribution-NonCommercial-NoDerivatives 4.0 International (CC BY-NC-ND 4.0) License. 